though not nearly so severe as the third one, confined him to bed for 14 days. He had been so crippled with the pain and the frequent disablement that he was anxious to take the chance of an operation and was urgent in his demand for it to be carried out at once. As the attack was somewhat milder than the others I elected to wait until his temperature remained normal for a day or two and not to delay the operation for a longer period in order that the adhesions might not be too firmly organised.

The operation was performed on Feb. 9th in the patient's home. Dr. Hamilton administered chloroform and I had also the advantage of the able assistance of Mr. Corrigan and Mr. M'Ginn. In addition to ordinary cleanliness the site of the operation was prepared by washing with Parke and Davis's germicidal soap and the application of biniodide of mercury ( 1 in 500 in methylated spirit). A compress wet with 1 in 1000 potassio-mercuric iodide was kept on until just before the operation. The instruments, dressings, and sutures, \&c., were sterilised in a steam steriliser before the operation. The steriliser was kept working during the procedure, the instruments alone being removed from it and placed in 1 in 1000 potassio-mercuric iodide. Our hands were prepared by washing and scrubbing in germicidal soap and then soaked in a saturated solution of permanganate of potash, decolourised in a solution of oxalic acid, and finally rinsed in 1 in 2000 potassiomercuric iodide. The usual incision was made over the appendix; I had hoped, but it was found impossible, to carry out the proceeding by McBurney's method. After separating the fibres of the external oblique with a little difficulty, as this muscle was hard and infiltrated, I found the structures below this to be inseparable and indistinguishable. Scraping cautiously through what I took to be the internal oblique, the ascending colon presented itself and proved to be adherent to the abdominal wall from the cæcum almost as far as the costal margin. Before completely separating all the adhesions an effort was made to locate the appendix but it was fruitless. The only thing now to do was to free the caput from its adhesions and explore the usual situations. The process of separating these adhesions was a long and tedious one, as they were tough, thick, and vascular, and the small intestine and colon seemed to be indiscriminately mixed and bound together by strong bands. The cæcum and the colon were then entirely freed from the abdominal wall on each side of the wound. A further search then revealed a hard tumour behind the colon, towards its outer side, resting on the iliacus muscle, just above the anterior superior spine of the iliam. The readiest mode of access to this tumour would have been at the outer side of the colon. but the inflammatory thickening here was almost cartilaginous and was impossible to work through. Returning to the inner side the cacum was lifted upwards and outwards and the tumour, which proved to be the appendix curled cochlealike, was shelled out of the muscle. The appendix was somewhat of the fotal type. It was considerably thickened and about two inches in length and a little over one inch in circumference at its base. It contained a concretion which apparentily consisted of frcal remnants. The route which the appendix had taken seemed to me to be through the subcrcal fossa, behind and to the outer side of the crcum and colon. It was removed by circular amputation, ligatured, and the flaps were united with fine silk and inverted. The h:morrhage from the adhesions was very considerable, but was readily controlled by forceps and pressure with sterilised mops. The ornentum was brought down to cover, the denuded colon and cæcum, the abdominal wound was sutured with silkworm gut, and sterilised gauze dressings were applied, the whole proceeding lasting just under two hours. The after course was uneventful. The stitches were removed on the fifteenth day. The wound healed rapidly by first intention, and except for a stitch abscess required no attention and the patient returned to business on April 3rd.

The important point in this case is that there was no pus. If an abscess had been found during the operation or if pus had formed and perforated during any of the attacks of illness one could hardly have hoped for so favourable a result in such a complicated case. Some may think that such a case would do well enough treated on medical lines, but most will agree with Mr. Mayo Robson's application of the rule, "When in doubt operate," and with the dictum of the late Mr. Greig Smith as regards suspicious appendices that " it is doubtful whether true wisdom and real caution do not abide with the bolder policy." I may finally point out that the observation of Byron Robinson that pain on brisk walking in cases of chronic appendicitis is due to the diseased appendix being within range of the action of the ilio-psoas would receive support from this case.

Newport, Mon.

\section{CARBOLIC ACID AS A TEST FOR ALBUMIN.}

\section{BY WALTER COLQUHOUN, M.A., M.B., C.M. Glasg.}

EARLY in the course of my practice $I$ was led to investigate the delicacy of our common tests for albumin and to search for another test which would have the delicacy of the nitric acid test without its fallacies. A patient had come to me suffering, I believed, from chronic interstitial nephritis. I could not find albumin in his urine by the heat test except on two or three occasions when there was scantiness instead of excessive excretion of urine. The nitric acid test showed a trace of albumin apparently, but my confidence in that test was lost on discovering crystals after withdrawing some of the urine from the region of the cloud and examining under the microscope, and this occurred when the specific gravity of the urine was only 1012. The picric acid test was also unsatisfactory and $I$ was led accordingly to seek a new test and to determine, en passant, another point on which I had no information-namely, what is the exact loss per diem of albumin when a trace is discovered in the urine. After a considerable amount of experimenting I chose a saturated solution of carbolic acid in absolute alcohol as a test equalling in delicacy the nitric acid test and giving perfect satisfaction after a short experience in working it.

One part of carbolic acid is soluble in about 20 parts of water at $60^{\circ} \mathrm{F}$. or perhaps in about 13 parts if the solution has been made by the aid of heat; it is very soluble in alcohol (six in one approximately), in ether, or in glycerine. The test solution having been made by dissolving carbolic acid to saturation in absolute alcohol I float a few drops of the solution on the top of the fluid to be tested by means of a pipette. Owing to the greater solubility of carbolic acid in alcohol than in water the layer of testing fluid on the surface becomes opaque and rather milky-looking owing to the separation of carbolic acid as water is imbibed in the transfer between the urine and the alcohol. As the alcoholic solution of carbolic acid imbibes more water and becomes heavier drops also of a milky appearance on their surfaces may detach themselves and fall to the bottom of the test-tube. If much albumin be present the whole of the fluid to be tested may become milky and the alcoholic layer may settle quickly to the bottom of the test-tube with large milk-white flakes of albumin attached to it. In the case, however, of the presence of only a small quantity of albumin the test-tube must be allowed to lie for some time just as in the nitric acid test, and the presence of albumin will be denoted by a milkiress extending to a certain depth below the alcoholic layer. As has already been remarked, milkylooking drops of the alcoholic solution of carbolic acid may separate and fall to the bottom of the test-tube. This happens even when the alcoholic test solution is floated on top of pure water and, as has been explained, the milkiness is due to the imbibition of water and consequent separation of carbolic acid. That this milkiness is not necessarily due to albumin may be shown when only a trace of that substance is present by passing the bottom of the test-tube two or three times through the flame of a spirit lamp, when, carbolic acid being more soluble in warm water than in cold, the milky deposit at once clears up. The milkiness at the upper part of the test-tube below the alcoholic layer is, however, due to coagulated albumin and does not appear unless that substance is present nor is it dissipated by heat.

I tried solutions of carbolic acid in water, in ether, and in glycerine as tests for albumin, but none approached in delicacy the solution in absolute alcohol. The ethereal solution is floated on top of the solution of albumin. It shows also a milky layer below the ethereal solution, but the milkiness is slow in appearing and is not so pronounced as with the alcoholic test solution. I explain the greater delicacy of the latter test by the fact that the upper layer of the albuminous fluid to a certain depth comes to contain a mixture of alcohol and water and thus can bold more 
carbolic acid in solution than water alone can do. The solution of carbolic acid in glycerine is passed to the bottom of the test-tube. It also gives a cloud but only after a long period, owing to the slowness of diffusion, and it also does not give such pronounced results as the alcoholic solution.

To determine the delicacy of the test I made up a solution of white of egg and proceeded to determine the amount of albumin per cubic centimetre (c.c.) by placing three cubic centimetres of the solution in a weighing bottle, evaporating to dryness at $180^{\circ} \mathrm{F}$., placing the stopper in the bottle, cooling, momentarily removing the stopper, replacing it, and then weighing. Out of two estimations the first gave 0.0119 gramme of albumin per cubic centimetre of solution and the second gave 0.0121 gramme. Considering that the fluid was measured by a pipette the results are remarkably close and we may take the average, 0.0120 gramme, as representing the weight of albumin in each cubic centimetre of the solution which may be called solution A. One cubic centimetre of solution A was now added to 200 cubic centimetres of water and the mixture taken for testing with the various tests. I should mention here that the nitric acid test is commonly too carelessly done. I use a slender one cubic centimetre pipette to take up the nitric acid. The outside of the pipette is then wiped and the nitric acid is passed to the bottom of the test-tube containing the albuminous fluid. After delivery the upper end of the pipette is again closed by the finger to prevent admixture of the fluids during withdrawal and the pipette is withdrawn. The results of the first series of tests were as follows:- Heat test: Could not affirm presence of albumin by this test. Picric acid test: Clear by transmitted light; slight impairment of clearness by reflected light with the tube held against a dark background. Nitric acid test : Ring developed after an interval. Carbolic acid test: Milkiness in upper part of the tube; slight deposit of albumin finally.

The next series of tests were done with a mixture containing one cubic centimetre of solution A to 400 cubic centimetres of water with the result that the picric acid fell out of the competition. Continuing the tests I have found that, after allowing the tubes to lie for a considerable interval, both nitric acid and carbolic acid showed the presence of albumin in a mixture containing one cubic centimetre of solution $A$ to 1000 cubic centimetres of water. Since one cubic centimetre of solution A contained 0.0120 gramme of albumin, dried at $180^{\circ} \mathrm{F}$., each cubic centimetre of the last mixture contained only 0.000012 gramme of albumin. This result brings out in a striking manner the great delicacy both of the nitric acid test and of the test by solution of carbolic acid in absolute alcohol The result works ou 5 at 0.0053 grain per ounce. Hence when a mere trace of albumin is found in the urine the amount of albumin (dried at $180^{\circ} \mathrm{F}$.) lost per diem on a 50 -ounce excretion of urine is only 0.265 grain, or rather less than one-third of a grain. The figures emphasise the fact that the anæmia accompanying cases of chronic interstitial nephritis is not at all dependent on loss of albumin, but rather on the ill-health following circulatory, alimentary, and nervous disorders. One cubic centimetre of solution A to .40 cubic centimetres of water gives a mixture which shows a pronounced milkiness on the application of the heat test, followed by considerable deposit of albumin. Yet even in such a case the patient would lose only $6 \frac{1}{2}$ grains of albumin (dried at $180^{\circ} \mathrm{F}$.) per diem on an excretion of 50 ounces of urine.

As regards the fallacies of the test $I$ have as yet found none which were not attributable to careless manipulation. Mucin may be precipitated by alcohol but I have had no trouble owing to its precipitation yet. I clear the urine, preferably by filtering, and it may be remarked in this connexion that the best Swedish filtering paper, such as is used for quantitative work, clears urine which a cheaper paper would allow to pass through cloudy. Another point worthy of mention is that cooling for a few moments, as, for example, by playing an ether spray on the upper part of the outside of the containing vessel, will often bring down a cloud of urates before filtering and is besides instructive as regards the degree of saturation of the fluid. both the nitric acid and the carbolic acid tests the urine should be diluted to about specific gravity 1010 . The proved delicacy of these tests allows plenty of margin for dilution and if after dilution no albumin be found its presence is in my opinion negligible. Indeed, I have found albu nin present in small quantities in the urine of such $a$ | large proportion of $m y$ patients that I am coming to regard its presence merely as a warning to me to make a careful examination and a guarded diagnosis. If the urine were always diluted before applying the nitric acid test the fallacies of that test would probably disappear. In the case of the carbolic acid test it is important that the fluid tested should not have too high a specific gravity since in that case the interchange between the alcoholic layer and the fluid tested is too slow. The dilution may be continued to a specific gravity below 1010 without affecting the result much if such a course be wished. In conclusion, I may state that since my investigations I can speak with certainty as to the presence or absence of albumin, whereas before $I$ had undertaken them I would not like to have certified in certain cases. Glasgow.

\section{d a dithror}

or

\section{HOSPITAL PRACTICE, BRITISH AND FOREIGN.}

Nulla autem est alia pro certo noscendi via, nisi quamplurimas et et dissectionum historias, tum aliorum tum proprias collectas habere, et inter se comparare.-MORGAGNI De Sed. et Caus. Morb., lib. iv. Procemium.

\section{ST. MARY'S HOSPITAL.}

A CASE OF STRANGULATION OF THE VERMIFORM APPENDIX IN THE SAC OF A FEMORAL HERNIA; OPERATION; RECOYERY.

(Under the care of Mr. EDMUND OWEN.)

THE vermiform appendix not rarely is found in the sac of an inguinal hernia and is generally accompanied by other portions of the bowel. It is decidedly exceptional to meet with it in a femoral sac and it is extremely rare to meet with it as the sole occupant of such a sac. The two cases recorded below, one of which occurred in the practice of St. Mary's Hospital and the other in that of St. Thomas's Hospital, are well-marked examples of this condition and very few other cases are to be met with in surgical literature. J. Langton ${ }^{1}$ had a case in which perforation of the included appendix had occurred into the sac; Keetley ${ }^{2}$ describes a case in which there were symptoms of strangulation and the only organ found in the sac was the appendix. W. H. A. Jacobson ${ }^{3}$ met with one case but no symptoms of strangulation were present. W. McAdam Eccles ${ }^{4}$ showed a specimen illustrating this variety of hernia ; the patient had died after perforation of a carcinomatous ulcer of the stomach. G. P. Newbolt has recorded a case ${ }^{5}$ in which some obscure abdominal symptoms were present and he quotes a similar case recorded by Annandale. L. A. Bidwell has met with two cases of this rare condition ${ }^{6} ;$ in both of these the herniated viscus was returned after Gimbernat's ligament had been notched, and the patients did well ; in neither case had there been any symptoms of strangulation. In all these cases, as well as in the two recorded below, the appendix vermiformis was the sole occupant of the sac of a femoral hernia. In a few cases there have been some symptoms suggesting intestinal obstruction, but they have been indefinite, and in most of the cases no severe symptoms were present but there was an irreducible femoral hernia. It has been suggested by W. McAdam Eccles ${ }^{7}$ that in cases where the appendix is said to be strangulated the symptoms are really due to inflammation precisely analogous to that which occurs when the appendix is in its normal position. This may be so in some cases, but in many of the instances quoted the process was so firmly fixed at the crural ring that it was necessary to nick Gimbernat's ligament before it could be retarned. For the notes of the case at St. Mary's Hospital we are indebted to Mr. P. G. A. Bott. I St. Bartholomew's Hospital Reports, vol. xxvii., p. 179.
\& Medical Press, 1890, p. 85. 3 Operations of Surgery, third edition, p. 637

4 Transactions of the Pathological Society of London, 1897, rol. xlviii., p. 87

5 Brit. Med. Jour., vol. i., 1897, p. 781.

6 Transactions of the Clinical Society of London, rol. xxx., p. 186. 1 Loc. cit. 